Jacques Montplaisir MD, PhD, Sleep Disorders Center, Sacre-Coeur Hospital, Montreal, Quebec, Canada H4J 1C5).

COMMNT. The prevalence of sleep terrors is high in infants (37\% at 18 months) and decreases by one half to approximately $20 \%$ by 30 months of age. Genetic factors play an important role in the etiology of this early childhood parasomnia, accounting for $>40 \%$ of the phenotypic variance for both 18 - and 30-month-old twins. The role of non-shared environmental factors is also significant, $>55 \%$ of the variance at both 18 and 30 months. Night terrors have a combination genetic-environmental etiology, but to date, no specific genes have been identified.

\title{
GENETICALLY DETERMINED EEG FINGERPRINT OF SLEEP
}

The influence of genetic factors on the individual profile of sleep electroencephalographic (EEG) power spectra at the 8 to $16 \mathrm{~Hz}$ frequency range during nonrapid eye movement (NREM) sleep was determined by recording 40 monozygotic and dizygotic twins during sleep. The study performed at the University of Rome and various international centers found that this EEG fingerprint of sleep showed a greater similarity in monozygotic than dizygotic pairs, with a $96 \%$ estimate of heritability. (De Gennaro L, Marzano C, Fratello F, et al. The electroencephalographic fingerprint of sleep is genetically determined: a twin study. Ann Neurol Oct 2008;64:455-460). (Respond: Dr De Gennaro, Department of Psychology, Section of Neuroscience, University of Rome "Sapienza," Via dei Marsi, 78, 00185 Rome, Italy. E-mail: luigi.degennaro(a)uniromal.it).

COMMENT. Healthy humans have a unique profile of the sleep electroencephalographic (EEG) power spectra at the 8 to $16 \mathrm{~Hz}$ frequency range duing nonrapid eye movement (NREM) sleep. This fingerprint allows discrimination between individuals with a probability of $92 \%$ (De Gennaro L et al, 2005). These authors have shown that individual differences in this EEG fingerprint of NREM sleep are genetically determined. A genetic contribution has already been demonstrated for the awake-resting EEG alpha power, and also, for many sleep disorders, including night terrors, narcolepsy, obstructive sleep apnea, restless legs syndome, and Kleine-Levin syndrome.

\section{NEUROMUSCULAR DISORDERS}

\section{HAND INVOLVEMENT IN CHARCOT-MARIE-TOOTH DISEASE 1A}

Hand strength, function and disease-related symptoms were determined in 84 children, aged 2-16 years, with Charcot-Marie-Tooth disease type 1A (CMT1A) at University of Sydney, Children's Hospital at Westmead, and Royal Children's Hospital, Parkville, Australia. Hand weakness and dysfunction was present from the earliest stages of the disease and tended to worsen with age throughout childhood. Poor handwriting, weakness, pain and sensory symptoms also worsened with age. (Burns J, Bray P, Cross LA, North KN, Ryan MM, Ouvrier RA. Hand involvement in children with Charcot-Marie-Tooth disease type 1A. Neuromuscul Disord Dec 2008;18:970-973). (Respond: Dr Joshua Burns, 
Institute for Neuromuscular Research, The Children's Hospital at Westmead, Locked Bag 4001, Westmead, NSW 2145, Autralia. E-mail: joshuab2@chw.edu,au).

COMMENT. CMT1A is a demyelinating neuropathy characterized by progressive muscle weakness and atrophy. The peroneal muscles are involved first, causing a striking stork-like gait, and weakness and atrophy of the upper extremities is initially limited to the intrinsic muscles of the hands. The authors comment that the hand involvement is frequently under-recognized in the early stages.

\section{HEARING LOSS IN FACIOSCAPULOHUMERAL DYSTROPHY}

The clinical presentation of facioscapulohumeral dystrophy (FSHD) with unusual large $4 \mathrm{q} 35$ deletions was studied with attention to hearing loss. Hearing function was examined by otoscopy, audiometry and auditory-evoked brainstem responses. Data obtained from 6 patients with EcoRI 4q35 fragment size, ranging from 10 to $13 \mathrm{~kb}$, were compared with those of 28 similar subjects reported in the literature. Sensorineural hearing loss occurred in 4 patients who had an infantile-onset dystrophic phenotype. Hearing loss was associated with mental retardation in 3 and epilepsy in 2. Hearing was mildly impaired in the remaining 2 of 6 patients. When the data from 28 similar cases reported in the literature were combined with that from the 6 patients examined, $68 \%$ had auditory impairment. Hearing loss is a characteristic feature of FSHD patients with a large $4 \mathrm{q} 35$ deletion. When considering only cases with 10-11 kb fragment size, FSHD is associated with early-onset dystrophic phenotype, mental retardation in $92 \%$ and epilepsy in $58 \%$. (Trevisan CP, Pastorello E, Tomelleri G et al. Facioscapulohumeral muscular dystrophy: hearing loss and other atypical features of patients with large $4 \mathrm{q} 35$ deletions. Eur J Neurol Dec 2008;15:1353-1358 (Abstract)).

COMMENT. Facioscapulohumeral dystrophy with sensorineural hearing loss and Coats' syndrome was described by Taylor DA et al (Ann Neurol 1982;12:395). Coats' syndrome includes congenital retinal dysgenesis with telangiectasia and retinal detchment. A PubMed search of the literature found 8 reports of FSHD and sensorineural deafness, dating from 2008 to 1985 . One case with epilepsy was complicated by infantile spasms at 6 months of age, the dystrophy presenting at 3 years, and sensorineural deafness noted later (Akiyama C et al. No To Hattatsu 1991;23:395-399). All 6 patients reported with facial diplegia in the first year of life and subsequent development of FSHD had sensorineural deafness (Korf BR et al. Ann Neurol 1985;17:513-516).

\section{NEONATAL DISORDERS}

\section{HIPPOCAMPAL VOLUMES IN PRETERM INFANTS}

The relation between neonatal regional brain volumes and working memory deficits at age 2 years was investigated in 156 very preterm children born at the Royal Women's Hospital, Melbourne, Auatralia, prior to 30 weeks gestation or weighing $<1250 \mathrm{~g}$. Very preterm children who perseverated on the working memory task had significantly smaller 